\title{
Repertorios anticoloniales en Plaza Dignidad: desmonumentalización y resignificación del espacio urbano en la Revuelta. Santiago de Chile, 2019
}

Anticolonial repertoires in Dignity Square: statues torn down and resignification of urban space in the Revolt.
Santiago of Chile, 2019

Ivette Quezada Vásquez

Universidad de Santiago de Chile, Chile

ivette.quezada@usach.cl

Claudio Alvarado Lincopi

Pontificia Universidad Católica de Chile, Chile

cdalvarado@uc.cl

\section{Resumen:}

Este trabajo desarrolla una propuesta de análisis en torno a los repertorios de acción que pusieron en cuestión los símbolos de la nación moderna y al proyecto urbano neoliberal, como elementos civilizadores. Proponemos que la narrativa monumental ha sido tensionada por el despliegue de una producción estética que ha revelado sus violencias y exclusiones históricas.

El centro de Santiago fue el escenario donde se desplegaron diversos repertorios que hablan de las múltiples temporalidades que habitamos, entre ellas la temporalidad colonial. En este sentido, creemos que la Revuelta tuvo un carácter chi'xi, siguiendo las ideas de Silvia Rivera Cusicanqui, es decir, operaron repertorios y estéticas yuxtapuestas desde donde se impugnaron las políticas de identidad del estado chileno. Asimismo, como parte de este proceso, se desplegaron nuevos usos, significados y nombres en el espacio urbano, a modo de un quehacer insurgente cuya densidad retorica todavía nos desborda, sigue abierto y en disputa.

Palabras ClaVe: Desmonumentalización, ch'ixi, Revuelta, Urbanismo insurgente.

\section{Abstract:}

This work develops a proposal for analysis around the repertoires of action that questioned the symbols of the modern nation and the neoliberal urban project, as civilizing elements. We propose that the monumental narrative has been strained by the unfolding of an aesthetic production that has revealed its historical violence and exclusions.

The center of Santiago was the scene where various repertoires were displayed that speak of the multiple temporalities that we inhabit. In this sense, we believe that the Revolt had a Chi'xi character, following the ideas of Silvia Rivera Cusicanqui, that is to say, juxtaposed repertoires and aesthetics operated from where the identity policies of the Chilean state were challenged. Likewise, as part of this process, new uses, meanings and names were deployed in the urban space, as an insurgent task whose rhetorical density still overwhelms us, is still open and in dispute.

KEYWORDS: Statues torn down, ch'ixi, Revolt, Insurgent urbanism.

\section{INTRODUCCIÓN}

En diferentes partes del país desde la tarde del 18 de octubre del 2019 se comenzaron a suscitar diversas acciones de desmonumentalización de íconos en el espacio público que representaban a colonizadores españoles, autoridades políticas y militares de la nación. En diversas ciudades como Arica, La Serena, Temuco, Concepción, Punta Arenas, Santiago, entre otras, se sacaron o intervinieron monumentos públicos. Todas distintas en su operación, pero no así en la profundidad de su resignificación como denuncia y como acto de justicia, abrieron como pocas veces una disputa pública por la memoria y el relato histórico. 
Como nunca los monumentos tomaron un protagonismo que abrió reflexiones emergentes. Por ejemplo, el historiador José Luis Martínez interpretó tempranamente los procesos de desmonumentalización como "batallas por la historia" (2019). Estas batallas para la antropóloga Francisca Márquez se desenvolvieron además entre los "escombros de la ciudad neoliberal" (2019). Es decir, en primer momento, la desmonumentalización se leyó como una disputa por la historia en plena crisis del modelo económico instalado en dictadura. Sumado a lo anterior, y desde donde nosotras aferramos nuestra hipótesis de trabajo, emergieron reflexiones que comenzaban a hablar de "gestos anticoloniales" (Allende, 2019) para referirse al repertorio desmonumentalizador, tal como indicó también el historiador mapuche Herson Huinca en su texto "El derribo de estatuas en las plazas de Chile y Wallmapu. La des-monumentalización de los iconos de la memoria histórica colonial" (2019). Por cierto, junto con estas reflexiones surgieron acciones de recopilación y archivo como la plataforma Instagram Monumentos IN $\operatorname{cómodos}^{1}$ o el fanzine La Descolonizadora. Cada una de estas lecturas y plataformas fueron engrosando una reflexión anticolonial sobre la desmonumentalización vivida en Chile durante la revuelta.

Precisamente, este trabajo se concentrará en observar un caso particular de los repertorios desmonumentalizadores desplegados durante la revuelta en el centro de Santiago, las gestadas en plaza Dignidad. Son ideas que han surgido desde el estar y el participar, desde la gestación de acciones y la conmoción de sentirse habitantes de momentos singulares y profundos. Habitamos esos días de revuelta, pudiendo ser testigos también de cómo las calles se desbordaban de palabras, de expresiones gráficas, cuerpos y sonidos que transformaron la movilidad cotidiana de la ciudad neoliberal. Allí, el patrimonio como parte de la planificación de un urbanismo funcional, que administra el habitar para el trabajo y la producción, se vio confrontado ante una imaginación radical que puso la dignidad de la vida como un modo político de habitar el mundo: un urbanismo insurgente, humano y descolonizador (Miraftab, 2018).

Con todo, nos preguntamos, ¿cuáles son los sentidos profundos del repertorio desmonumentalizador? ¿bajo qué herramientas teóricas es factible interpretar estos hechos? ¿Cómo la desmonumentalización tensiona al discurso oficial del patrimonio? ¿cómo todo ello nos habla de las disputas por la ciudad? Para intentar responder, en parte, estos cuestionamientos nuestro trabajo abordará repertorios desplegados en la plaza de la Dignidad en la revuelta a partir de reflexiones teóricas que nos permitan una comprensión anticolonial del fenómeno.

\section{MONUMENTOS: LA MEMORIA SEDIMENTADA DE LA NACIÓN COLONIAL}

Comprendemos la narrativa monumental como base del relato de la nación moderna que ha proyectado su continuidad histórica a partir de dispositivos como el patrimonio cultural (cf. Marquéz, 2018). Para la compresión de esta relación, particularmente pensando en América Latina, debemos situar los debates anticoloniales como cruciales, sobre todo pensando en las prácticas simbólicas sedimentadas en los espacios comunes de habitabilidad urbana que han servido como sustentos narrativos de la continuidad del patrón colonizador. Así, se articulan dos dimensiones de análisis: el hecho monumental y la narrativa de la nación blanqueada. Intentaremos abordar ambas dimensiones.

Como es de suponer, las estatuas que aparecen por plazas públicas, avenidas y edificios de las ciudades de América Latina desde el siglo XIX, no han más que replicado lo que hicieron imperios, reinados e iglesias por siglos. Nuestras clases dominantes, muy bien informadas de cómo se fundan naciones e identidades comunes, erigieron urbes a semejanza de sus historias, de sus próceres, y nos convencieron de que sus mínimas experiencias eran las de todos, que sus padres eran nuestros padres: todo ello materializado en los monumentos públicos. Bajo este contexto, la pregunta por la patrimonialización del mobiliario escultórico urbano debe contener un sentido crítico, capaz de reflexionar sobre los usos del pasado como narrativas de legitimación de las actuales jerarquías sociales. Con ello, creemos atingente dotarnos de una reflexión teórica sobre el cruce entre políticas de memoria, monumentalidad y nación excluyente. 
La memoria, lo sabemos, siempre enfatiza los recuerdos que son significativos para el presente, se constituye desde un hoy edificando imágenes que permiten organizar nuestros discursos y prácticas contemporáneas. De este modo, encontrar la realidad del pasado, eso que realmente sucedió como prometían los historiadores positivistas, siempre estará mediado por una carga contextual, por tiempos y espacios en donde se narra lo ya acontecido, en definitiva, por lugares de producción de conocimiento (De Certeau, 2006). Ya lo indicaba Walter Benjamin cuando decía que "articular históricamente el pasado no significa conocerlo como verdaderamente ha sido. Significa adueñarse de un recuerdo tal como éste relampaguea en un instante de peligro" (Benjamin, 2007, p. 67).

En la memoria se articulan los prejuicios, los malestares, las situaciones familiares, los conflictos políticos, las crisis económicas, las transformaciones culturales, para presentar lo vivido como un determinante del hoy, positiva o negativamente. Existe entonces un uso selectivo de la memoria en donde intervienen procesos y actores diversos que construyen y formalizan relatos del pasado, "se trata de actores que luchan por el poder, que legitiman su posición en vínculos privilegiados con el pasado, afirmando su continuidad o su ruptura" (Jelin, 2002, p. 40). Con ello, pensar sobre los usos de la memoria y la historia, sus tránsitos, edificaciones y borraduras nos invita a dialogar con los contextos de elaboración y mutación de esas "verdades", muchas veces contradictorias y en disputa.

Lo anterior adquiere aún mayor complejidad cuando sabemos que existen políticas de la memoria que ocupan el espacio público para generar, a partir de ciertas lecturas, determinados discursos del pasado con fines políticos en el hoy (Jelin, 2002, p. 39-62). Estas operaciones simbólicas, desde el siglo XIX, han sido hegemonizadas en América Latina por los estados nacionales, quienes han hecho de la historia patria la religión de su institucionalidad, desarrollando conmemoraciones, monumentos y panteones a los que definen como héroes, fortaleciendo una identidad nacional construida a imagen y semejanza de nuestras oligarquías (Colmenares, 1997). Así, estas operaciones político-públicas de cosificación y propagación de una memoria, lo que Pollak denomina encuadramiento de la memoria, permiten "mantener la cohesión de los grupos y las instituciones que componen una sociedad, para definir su lugar respectivo, su complementariedad, pero también las oposiciones irreductibles" (Pollak, 2006, p. 25). La memoria, de esta manera, se nos presenta al mismo tiempo como un aglutinador y como un disociador, que nos entrega códigos de convivencia, identificación y segregación.

Ahora bien, esta supuesta función cohesionadora de la memoria no logra suprimir las contradicciones y tensiones de las sociedades; por el contrario, al existir políticas de la memoria dominantes que se plasman en el espacio público, visibilizan los malestares subterráneos al mismo tiempo que niegan esas otras memorias, dado que, como señala Enzo Traverso, "hay memorias oficiales alimentadas por instituciones, incluso Estados, y memorias subterráneas, escondidas o prohibidas" (Traverso, 2007, p. 48), las cuales se encuentran en conflicto, y que por tanto "al definir aquello que es común a un grupo, por un lado, se refuerzan los sentimientos de pertenencia, pero por otro, esas memorias pasan a ser imposiciones, formas específicas de dominación y de violencia simbólica" (Da Silva Catela, 2010, p. 121)

¿Qué recordamos entonces? Sin duda, no es lo que aconteció realmente, no podemos traer el pasado al presente sino es por medio de una interpretación en donde existen procesos de sacralización, mitificación y amnesia (Traverso, 2007, p. 29). La memoria, con ello, se trasforma en un campo de disputa, en donde lo político y lo cotidiano se funden para tramar narrativas que fundamentan la praxis de los procesos actuales. Aquí yace la posibilidad de la desmonumentalización.

Por otro lado, sabemos que la memoria se sedimenta, adquiere espacialidad en los llamados "lugares de memoria" (Nora, 2009), el relato del pasado está curtido en espacios, lugares, cuerpos, textos, objetos. En este sentido, las ciudades como espacios serían dispositivos cargados de experiencias, identidades y memorias. En ella, por supuesto, conviven múltiples temporalidades sedimentadas, haciendo de esta forma a la ciudad un "mosaico de imágenes entrelazadas, de espacios que adquieren unidad a partir de encontrarse unos sobre otros, de tiempos que se contrapuntean entre sí y se contradicen” (Salazar, 2006, p. 31) 
Esas ciudades entrelazadas son en definitiva imaginarios urbanos que transitan por calles y avenidas reconfigurando la ciudad física, permitiendo que las representaciones de la ciudad superen a la ciudad material, ya que "el imaginario crea imágenes actuantes, imágenes-guías, imágenes que conducen procesos y no solo representan realidades materiales o subjetivas” (Hiernaux, 2007, p. 20). De este modo, así como existen memorias, también existen ciudades múltiples y tensionadas que edifican redes y relatos para ser y estar en la urbe. Con ello, la desmonumentalización sería la materialización práctica que devela aquellas tensiones.

Es que los derroteros del poder en las ciudades han fabricado espacios en donde se sienten las jerarquías, se perciben, territorios en donde los relatos oficiales hacen advertir a nuestros cuerpos que deben comportarse respetuosamente, deben normarse más de lo común, en definitiva, nuestros cuerpos y discursos deben asumir solemnidad frente al poder; romper la barrera de la solemnidad nos ubica en estado de protesta. De este modo, así como las leyes, la ciudad también es performativa (Butler, 2002).

Los espacios en donde se visibiliza el poder estatal a menudo son plazas públicas, juzgados, ministerios, casas de gobierno, y en cada una de ellas encontramos monumentos, esculturas que nos recuerdan cotidianamente quienes son nuestros padres fundadores, "la ciudad elige que recordar, esto es, qué hacer realidad, y en sus piedras esta la huella de ese recuerdo" (Silvestri, 1999, p. 43). En esas piedras está fijado lo que nuestras clases dominantes optaron recordar. De esta manera las políticas de la memoria estatales y los imaginarios urbanos hegemónicos erigen los monumentos, les dan contenido y forma.

En palabras de Achugar el monumento opera como la "objetivación de la memoria" (Achugar, 1999, p. 141), pero esta objetivación, este intento por vencer tiempo y olvido, no es neutral, dado que, como explica el mismo Achugar, la monumentalización de la memoria se emplea

“para construir o consolidar la identidad del ciudadano y de la polis. En ese sentido, se trata de la memoria de quienes tenían el poder y es obvio que quienes no pertenecían a la urbe eran considerados bárbaros o extranjeros que no hablaban el idioma de la polis y que no merecían ser objeto de la memoria oficial" (Achugar, 1999, p. 148)

Con ello, el monumento urbano que tiene una función de recuerdo y poder nunca es neutral, es un objeto cultural que trabaja para instalar un relato del pasado en el espacio público, proceso por medio del cual se convierte en objetivo, de este modo "el monumento de la memoria en piedra es, más que una representación de otra cosa es la cosa misma. El monumento es el objeto y el objetivo de la representación” (Achugar, 1999, p. 155). De esta manera, el monumento es una operación cultural analizable bajo su contexto de producción y difusión de una memoria específica, siempre cruzada por relaciones de poder, y ellas han sido el sustento de un espacio público celebratorio de las heroicidades elitarias.

Bajo este sentido, el monumento representa ideologías y coyunturas políticas que pretenden proclamarse como verdaderas, es un dispositivo destinado a obtener un resultado específico, es en definitiva la materialidad de un sentido del pasado que por medio de la utilización del espacio público se hace extendido y posiblemente primordial, como es el relato de la nación excluyente. Precisamente, para conseguir el resultado esperado, el monumento debe fijarse pisando otras memorias e identidades, construirse sobre experiencias que el poder no pretende recordar, dado que hacen doblar sus cimientos que parecen sólidos y duraderos. Tal como explica Achugar:

"el monumento, en tanto hecho monumentalizado, constituye la celebración del poder, del poder tener el poder de monumentalizar, [y] al mismo tiempo, la representación es un borramiento, una tachadura, una cancelación pues el monumento borra, tacha, cancela toda otra posible representación que no sea la representada por el monumento. La visibilidad del monumento vuelve invisible todo aquello y todos aquellos que el monumento niega o contradice" (Achugar, 1999 , p. 155).

Los monumentos entonces son ejercicios celebratorios del poder, y ello en el marco de un estado-nación ha sido un modo de conmemorar la historia oficial, que es en definitiva la memoria de los vencedores, las elites blancas y masculinas. Así, esta conjunción material, se ha dispuesto como un modo de reafirmar la narrativa de una nación excluyente. Son los monumentos unos de los modos públicos para construir un relato de "lo 
que somos" y así para legitimar la continuidad de lo señorial, ahora encubierta bajo un discurso de supuestos intereses comunes en el marco de la nación (cf. Luis Tapia, 2019). Es la continuidad colonial en tiempos republicanos, otro engranaje de la estructura de jerarquización que celebra los cuerpos y las biografías de hombres blancos miembros de las elites que todavía gozan de privilegios y dispensas materiales y simbólicas. Y acá adquiere sentido profundo la desmonumentalización, desde allí es posible leer un malestar contra la construcción elitaria del relato nacional, donde los héroes particulares de los sectores dominantes ya no son más los héroes de toda la comunidad política. Es quizás una impugnación contra aquel guión homogeneizante y señorial de actitud blanquecina, que ya incomodó hasta la saciedad. La desmomunetalización aparece entonces como un ejercicio destituyente.

\section{REPERTORIOS CH'IXI CONTRA LA NACIÓN COLONIAL}

Plaza Dignidad, ex Baquedano fue centro de las manifestaciones de la Revuelta en Santiago. Este lugar es reconocido como el límite simbólico entre el Santiago de los de arriba, los ricos, y de los de abajo, los pobres. En el oriente viven los sectores medios acomodados y la clase alta, allí se concentran los mayores ingresos del país. En el poniente, las comunas populosas, barrios y poblaciones de familias trabajadoras. Por años hemos cargado con esa frontera emblemática, la que ha sido ocupada como punto de encuentro para celebraciones de triunfos deportivos, el inicio de marchas y de manifestaciones políticas. Una diversidad de acontecimientos que no necesariamente se correspondían en sus motivaciones y visiones ideológicas. Entre estos, y dentro de este siglo, podemos mencionar la muerte de Augusto Pinochet en el año 2006, el rescate de los 33 mineros en el 2010, las concentraciones del movimiento estudiantil el 2011 o las celebraciones del triunfo de Chile en la copa América 2015. Diversas motivaciones y usos que no lograban fracturar del todo el flujo de la ciudad neoliberal.

Como custodio de esa frontera, aparece la figura del monumento al general Manuel Baquedano, militar, político y terrateniente chileno conocido por su participación en el proceso de consolidación del estado nación a partir de mediados del siglo XIX. Como militar fue parte de la mal llamada "Pacificación de la Araucanía", allí participó en reconocidos hechos de sangre, como lo fueron la invasión a Malleco y Reinaico en Wallmapu. Conocido también es su rol en la Guerra del Salitre, que gestó un proceso de invasión sobre territorios bolivianos y peruanos. Posteriormente, en 1891, tomó provisionalmente el mando del país en el marco de una guerra civil, en este contexto, entre el 29 y 31 de agosto, se desarrollaron en Santiago una ola de saqueos y destrozos que el general Baquedano no pudo contener.

Pero esto último sería un detalle no recordado para la oligarquía nacional, quien inauguraría de todas maneras en 1928, de la mano del presidente, el también Militar Carlos Ibáñez del Campo, un monumento en su honor en la plaza que llevaría su nombre. El monumento de bronce de más de 10 metros de altura y de cerca de una tonelada de peso, muestra a Baquedano con su uniforme militar en su caballo mirando imponente hacia el Santiago de los pobres. Como parte de la escultura, debajo de su caballo, aparece una mujer, en actitud sumisa, con una corona de flores de copihues, la "flor nacional", y en su retaguardia, la figura de un soldado desconocido con una placa que dice: "Aquí descansa uno de los soldados con que el General Baquedano forjó los triunfos del heroísmo chileno". Ambos, la mujer y el soldado como personas anónimas de extracción humilde eran recursos habituales en este tipo de escultura ornamental. Es que tal como señala Galindo, pensando en Benedict Anderson: "el imaginario nacional se alimenta de ese tipo de emblemas. Las tumbas del soldado desconocido constituyen una costumbre nacional moderna; no contienen resto alguno, pero están "llenas" de lo que él llama imaginerías nacionales fantasmales" (Galindo, 2007, p. 38). El monumento a Baquedano y todo lo que lo compone son aquel fantasma, emblemas que alimentan la idea de una nación armoniosa y unificada.

El monumento ha estado ahí por casi un siglo, una especie de guardián del orden nacional, mirando al poniente, al Santiago de los pobres, conteniendo quizás con su impronta y el despliegue por supuesto de la 
fuerza policial, todo evento que excediera las formas del "buen ciudadano" y la normalidad de los flujos y ritmos de la ciudad neoliberal. Pero tal como en 1891, Baquedano en el 2019 solo pudo observar atónito el despliegue de la protesta. Baquedano, como carne y como piedra, fue superado por la Revuelta.

Por eso la ocupación permanente de ese espacio a partir del 18 de octubre 2019 desestabilizaba hasta las entrañas a la nación neoliberal. A partir de ese día se llenó de cuerpos, bailes, cantos, la wenu foye (bandera mapuche), se hace parte de los repertorios de la movilización. Las convocatorias se hacían cada vez más masivas, llegando a más de 1 millón de personas el viernes 25 de octubre. Así, Baquedano desaparecía, entre la gente, las banderas, los lienzos y la sonoridad de la protesta. Estábamos ante una desmonumentalización por saturación y con ello un nuevo paisaje emergía, la plaza de la Dignidad.

Fue así como el 8 de noviembre los movilizados renombraron a la plaza Baquedano como plaza Dignidad. Cabe mencionar que este lugar ha tenido varios nombres desde su creación en 1872 como parte del primer plan de urbanización de Santiago de la mano de su intendente, Benjamín Vicuña Mackenna. Este fue el ideólogo de la segregación espacial encubierta en nombre del progreso y la nación, dividendo Santiago entre la ciudad propia, la civilizada y la ciudad impropia, de la barbarie (cf. Leyton y Huertas, 2012). Sus nombres fueron La Serena, Cristóbal Colón, Italia y Baquedano, siendo el del 2019 la primera iniciativa popular por renombrar y resignificar este espacio.

Esta disputa incluso se desenvolvió en las cartografías digitales, sin ir más lejos, en la plataforma Google maps el nuevo nombre permaneció algunas horas en contienda. Pero no fue solo una lucha por el nombre, una cuestión relevante es el hecho de hacer de ese espacio por fin una verdadera plaza. Es que realmente ex plaza Baquedano en su cotidiano no es más que una rotonda, no es una plaza, su naturaleza misma hace de este lugar un espacio centrifugo, que expulsa. Así, el cambio de nombre y su ocupación permanente, hizo de ese espacio de la ciudad un verdadero vértice ocupado, manchado, habitado, en definitiva, vivido.

Con todo, tras estas operaciones estatales de monumentalización ya descritos y los desbordes desmonumentalizadores gestados por la movilización, se fragua una vieja batalla estética en América Latina, una lucha por los relatos identitarios y las narrativas históricas sedimentadas en el espacio público. Y es curioso, las "guerras de las imágenes", como fue definida por Gruzinski (1994), adquiere centralidad ante sociedades con diferenciados usos de la escritura. Ante la falta de un modo de escribir unificado, pues la lucha sería estrictamente iconográfica, como lo fue en los primeros siglos coloniales. Así, uno tendería a pensar que en la medida que la "ciudad letrada" fue calando por todo el espectro social, las batallas simbólicas aparentemente se reducirían a los combates culturales bajo el formato escritural. Pero no. La operación escultórica y pictórica siguen profundamente actuales, por entre ellas se siguen desatando las tensiones por el guión de la comunidad política. 


\section{IMAGEN 1}

DE PLAZA BAQUEDANO A PLAZA DIGNIDAD, DE LOS FLUJOS DE LA NORMALIDAD NEOLIBERAL A LA SATURACIÓN DE LA REVUELTA. EL MONUMENTO DESAPARECE ANTE LA MULTITUD, UNA DESMONUMENTALIZACIÓN POR SATURACIÓN.

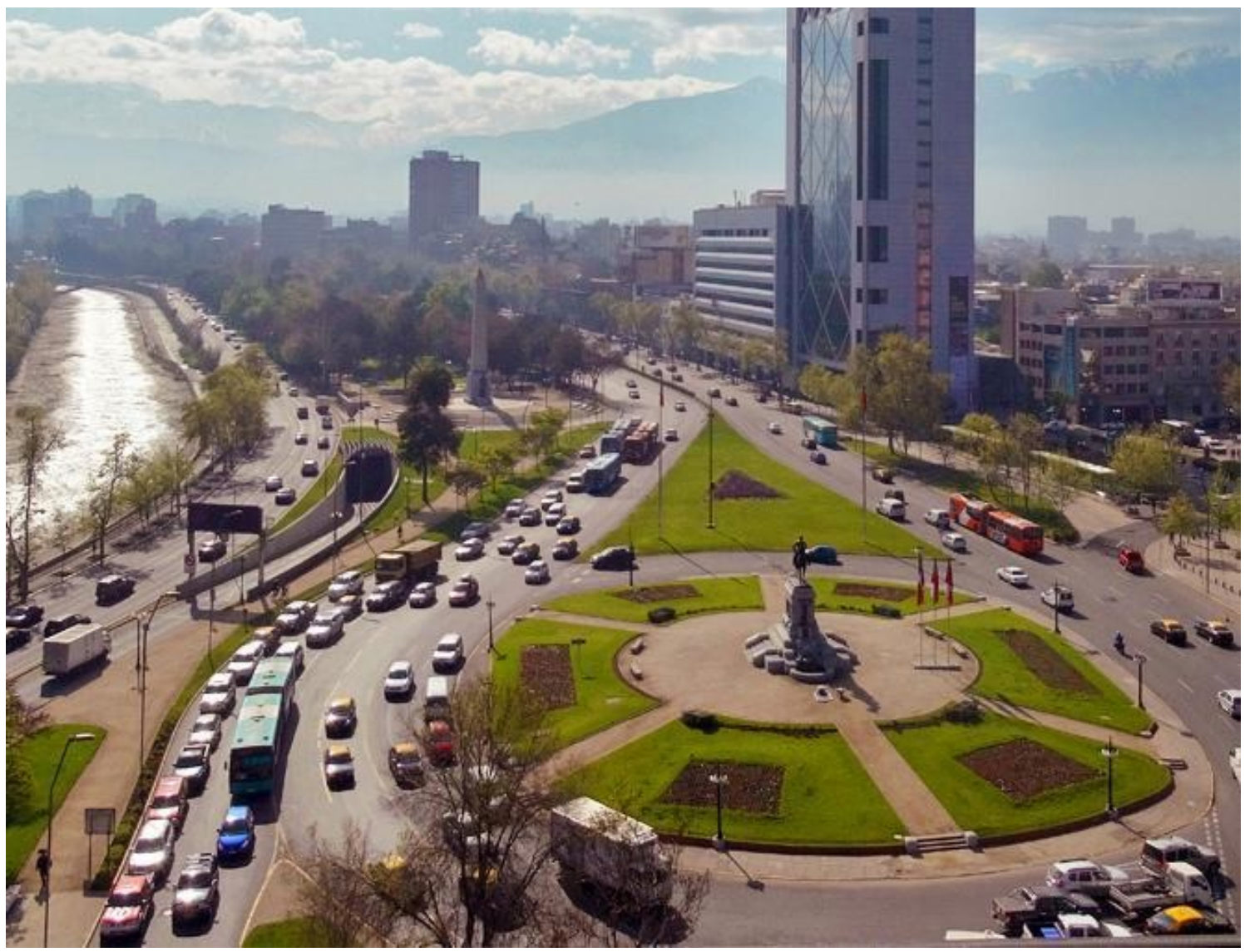

Plaza Baquedano, vista poniente a oriente. Fotografía, Enterreno, 2015 (Amaro, 2018).

IMAGEN 2

Marcha del viernes 25 de octubre en Plaza Dignidad, Fotografía DW Agencia (“La marcha...”, 2019).

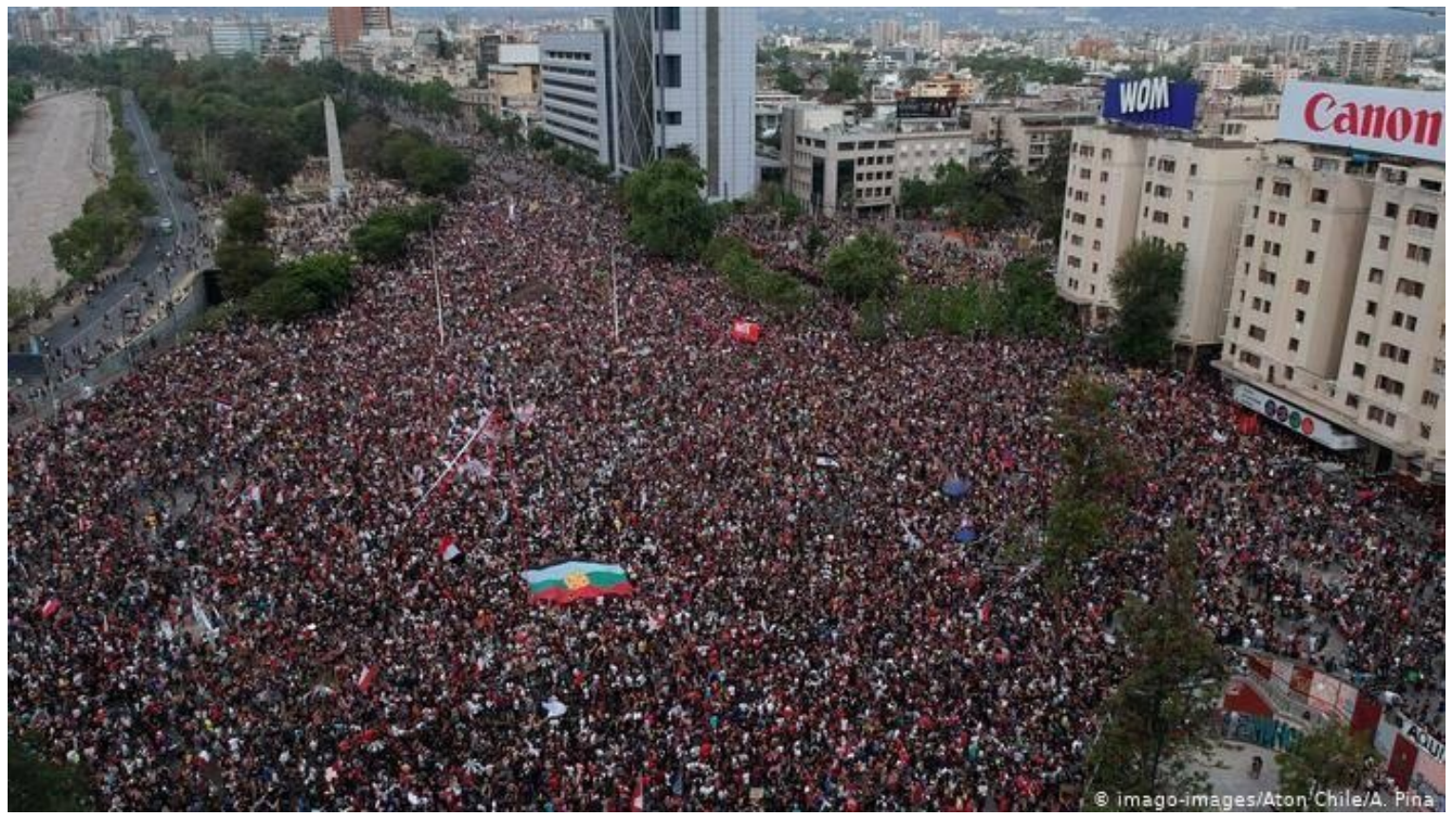


Desde nuestro punto de vista, en estas batallas iconográficas perdura aquello iniciado en los primeros siglos de colonización. Por un lado, las ansias por el blanqueamiento, que es la intención homogeneizante y unificada del espectro visual del espacio público, ya sea como religiosidad universal o, más tarde, como patria uniformada. Por otro lado, la pulsión barroca del mundo indígena que, bajo el ejercicio del decoro a lo presentado de modo inmaculado, logró absorber, y finalmente autonomizar una estética jaspeada, donde el ícono blanqueado sufre intervenciones decorativas que hacen del objeto homogéneo una obra irregular, cubierta de capas adosadas de modo irrevisable. Blanqueamiento versus barroquismo, en el decir de Bolívar Echeverría (2010), ante nuestros ojos y sobre los monumentos de la patria señorial.

Es que uno de los elementos más notorios de la movilización desplegada desde el 18 de octubre es la pulsión contracultural que reina en las calles. Es una contracultura que despliega su potencial ya sea arrancando la escultórica disposición de la historia patria, o manchando su pedestal, haciendo de la homogeneidad del cobrizo monumental un jaspeado inentendible de buenas a primeras, un abigarramiento estético que comienza a disputar desde las formas el ethos futuro, resquebrajando la razón colonial que ha buscado por siglos triunfar en la "guerra de imágenes" iniciada en 1492.

Un denso pasado hoy actualizado en las calles del país, donde las mayorías inscriben sus críticas y quimeras desde la pluralidad, mientras que los defensores del señorío, del statu quo, de la "normalidad", expanden su sentir desde la borradura, desde el reaccionario blanqueamiento. Elocuente de esta guerra fue aquella mañana, posterior al "acuerdo de paz", aquella "cocina" que todavía intentamos hacer "olla común”, cuando Plaza Dignidad amaneció de perfecto blanco, intentando borronear el entintado multicolor que es hoy el punto cero de la movilización social. La tachadura, la negación de la alteridad como prerrogativa de la hegemonía blanquecina, la cual solo acepta al "otro" cuando no hiere, cuando no mancha, es decir, cuando es mestizaje como crisol blanqueado o como pastiche mercantilizado del folclor nacional. Pero cuando el rotaje mancha, cuando busca ser realmente parte de la comunidad política, su acción es leída como afrenta, como profanación. La supuesta alma de la nación, el mestizo popular, el chileno, termina paradójicamente ultrajando lo patrimonial, se hace indio nuevamente, vive lo que siempre le ha tocado a la alteridad radical, la mano más perversa del poder. Es lo que se ha escuchado en las calles: "ahora los chilenos experimentan lo que por tantos años les tocó soportar a los mapuche”.

Aparece así, en las bocas de las elites, nuevamente, la frase de su congoja: "rotos de mierda". Sarmiento resucitado, y el viejo peso colonial encuentra sus cauces, nuevamente las elites temen, sienten la presión de ser latinoamericanos y convivir con su mayor enemigo, con la barbarie. Y otra vez no nos entienden, venimos de lejos, de las antípodas, de otros mundos, somos los alienígenas como perfectamente sentenció Morel, la primera dama. Y como no recordar aquella frase que resume intensamente la historia de Chile, esa pronunciada por Frei Montalva en los pasillos de las Naciones de Unidad el año 1974, todo según el poeta Armando Uribe:

Toda la historia de Chile consiste en evitar que los indios atreviesen el río Bio-Bío (la frontera de guerra con los araucanos); con el gobierno de Allende y la Unidad Popular, los indios lo atravesaron; ipor eso se produjo el golpe (citado en González y Sampieri, 2018, p. 17). 
Los privilegiados, los amos, y sus temores, todo se revive. Portal La Dehesa invadida como otro repertorio de acción post 18 de octubre, y las elites desenfrenadas, haciendo llamamientos para el control y el orden, el indio ha cruzado nuevamente la frontera, el mestizo popular, el criollo del bajo pueblo se vuelve indio, rotos de mierda, aparecen sus estigmas, el peso del colonialismo que lo republicano no ha detenido, solo intentó infructuosamente higienizar mediante un mestizaje por blanqueamiento. Mientras, las mayorías sienten tan cerca la redención de los muertos, por eso hay alegría y llanto, todos los tiempos se condensan en nuestro aquí y ahora, entonces lo barroco se vuelve irrefutable, categórico, no sabemos para donde vamos, solo sabemos que vamos con todos, o con muchos, aparecen entonces cientos de banderas, de consignas, de graffitis, dibujos, performances, cuerpos, nuestro barroquismo emerge a superficie. Y en esta guerra de imágenes estamos, actualizando la herida que ha cruzado por más de cinco siglos nuestro continente.

Entonces reverbera desde las formas, desde los quehaceres estéticos, otros modos de pensar e imaginar la comunidad política. Es una negación de la homogeneidad impuesta, y una exploración por las múltiples posibilidades, imaginarios y utopías que cohabitan Chile. Acá emerge un modo de pensar, uno abierto al contacto, sin temor a la impureza, confuso y en movimiento, profundamente ch'ixi. Es decir, estamos en presencia de un momento destituyente y constituyente: se destituye mediante la desmonumentalización, se constituye desde el barroco que emerge en la movilización. El mestizaje se reinventa, deja de ser un crisol de razas, un fundido acabado y homogéneo, y se inscribe ahora como quehacer constante, como mezcla inestable, siempre en elaboración.

Y así, durante la revuelta se entretejieron espacios, cuerpos, experiencias y tiempos que fueron desplazando las reglas de ciertos mobiliarios urbanos que previamente nos parecían indiferentes o inamovibles. Los ornamentos del patrimonio nacional no nos resonaban, los símbolos del colonialismo nos incomodaban, la ciudad neoliberal nos abrumaba. Con la revuelta produjimos o develamos un paisaje de resistencia (Barria, 2020), de identidades múltiples. Precisamente, nuestra reflexión apunta a señalar que la revuelta cristaliza una emergencia ch'ixi, categoría acuñada por Silvia Rivera Cusicanqui para dar cuenta de una identidad manchada, impura, desde donde lo indix aflora como una contradicción y a la vez como un espacio de reconocimiento mutuo. Una posibilidad de ser y habitar distintos mundos al mismo tiempo (Rivera, 2018). Desde nuestro punto de vista, todo esto se manifestó en Santiago mediante el despliegue de acciones de acumulación y yuxtaposición, que no significaron, necesariamente, la sustitución definitiva del relato urbano, pero si su resignificación y apropiación por parte de los movilizados, una revaloración del patrimonio desde una perspectiva $c h$ 'ixi, que impugnó las políticas de identidad del estado chileno.

Ese despliegue de repertorios no puede sino pensarse desde una dimensión territorial en sus múltiples temporalidades. En esa línea, resulta importante mencionar trabajos como el de Francisca Fernández y su artículo: "Memorias en resistencia: festividades y ritualidades andinas en Santiago de Chile" (2018), donde aborda, por un lado, lo festivo como un lugar de memoria y, por otro, lo urbano como un lugar posible de etnificación. Con ello, Fernández reconoce la impronta andina de Santiago a partir de las diferentes investigaciones arqueológicas y etnográficas que desarrollan la idea de un Mapocho andino, cuestión altamente denegada por el relato oficial de la ciudad. Así, Santiago se vuelca un espacio donde diferentes ritualidades articuladas con lo político reelaboran desde el presente lo andino y lo indígena en la ciudad. Si bien el texto se concentra en el quehacer de grupos indianistas en la capital en estos últimos 10 años, resulta un ejemplo de las múltiples acciones que venían resignificando espacios que con la revuelta se amplificaron en manifestaciones sin referentes y que nos permitió encontrarnos con el territorio pluricultural que históricamente ha sido este valle. 
Así, plaza Dignidad fue un escenario en donde el archivo, entendido como la cultura material fijada en el espacio, y el repertorio, comprendido como acciones colectivas corporalizadas (Taylor, 2017), se imbricaron en la movilización para construir y trasmitir conocimientos. El monumento de Baquedano como archivo urbano se vio impactado por una serie de repertorios performativos, que lo hicieron desaparecer bajo un sentido univoco y homogéneo, y lograron introducir en un devenir a un artefacto que buscó desde su origen ser fijo e inamovible, y este transitar durante los meses de revuelta no busco necesariamente un horizonte preconcebido, más bien fue cada día de intervención viraba, ampliándose hacia nuevos contornos.

\section{REPERTORIO CH'IXI COMO URBANISMO INSURGENTE.}

Baquedano un día era un barrista, al siguiente era mapuche, otro día era una centauro feminista, la mayoría de las veces simplemente una suerte de ekeko desacralizado. La monumentalidad cosificada del guión patrio, transformada en documento del archivo urbano de la nación, mediante una serie continua de repertorio mestizos, en el sentido de mixtura y heterogeneidad, se desvaneció, dejó de ser escultura sacra, y devino en lienzo, claro, no por ello neutral a modo de tabula rasa, sino que un lienzo cargado de politicidad, el perfecto muro del poder que el rayado iconoclasta siempre soñó intervenir.

Desde esta grafía de intervenciones múltiples, nosotros creemos, emerge otro modo de pensar y proyectar la ciudad. Es que las batallas estéticas no se reducen a dimensiones sobre la belleza como esfera autónoma de la realidad, sino que ante todo es un debate político. Debate que viene fraguándose por siglos bajo el modo de una "guerra de imágenes", que es finalmente los combates por la narración de lo común, lo cual es siempre una definición por los futuros posibles. Y este debate, como se ve, se desenvuelve espacialmente.

Ahora bien, aquí los repertorios barrocos que se desenvolvieron por entre las calles céntricas de la ciudad no solo han puesto en tensión el guion nacional, sino que, de algún modo, y esta es la dimensión más vacilante de estos repertorios, pensamos, también han logrado poner en aprietos a la fórmula contemporánea de proyectar la ciudad, guiada por el capital inmobiliario. Es que plaza Dignidad se encuentra en el eje fundamental de Santiago, la icónica Alameda. Precisamente durante los últimos años se ha abierto un debate sobre la remodelación de este eje, y por supuesto los inmobiliarios han sido central en estas discusiones. Así, luego de la revuelta y considerando su escenario urbano fundamental en la Alameda y la plaza Dignidad, ¿qué ocurrirá con estos debates? ¿Quiénes son los llamados a imaginar el eje principal de la ciudad para el siglo XXI?

Y esta disputa no es menor, sobre todo si consideramos que quizás el más grande interventor actual del espacio urbano sea el capital inmobiliario, articulado con el capital financiero y bancario, los cuales han desplazado a las instituciones públicas y/o comunitarias como hacedoras de ciudad. La planificación urbana, aquel dizque fortín estatal para pensar las ciudades como totalidades, ha quedado en desuso por la planificación cortoplacista del capital. Mediante la lógica de rentabilidad máxima se edifica la ciudad neoliberal, generando nuevas centralidades vinculadas a las mercancías.

En América Latina, y en Chile por supuesto, este capital inmobiliario ha construido grandes proyectos de renovación urbana mediante lo que se ha definido como corredores urbanos, que era precisamente el plan para la Alameda y plaza Dignidad. El capital inmobiliario, por cierto, no actúa sólo, tiene la venia de las administraciones políticas de corte neoliberal, quienes han definido espacios de crecimiento urbano 
muy específicos, generando muchas veces un desarrollo urbano por medio de un fenómeno de implosión, es decir, densificando áreas concretas de la ciudad, todo esto gracias "al incremento de inversiones y negocios inmobiliarios realizados con el propósito de rentabilizar excedentes de capital mediante operaciones de destrucción creativa y reutilización de áreas centrales y peri-centrales de la ciudad heredada de la fase anterior" (De Mattos, 2018), y esto ha sido fundamentalmente Santiago centro durante las últimas décadas. En fin, con todo, la metrópolis actual pierde definitivamente una de la sustancia ideológica de las urbes, la cosa pública debatida en el escenario democrático por excelencia, la ciudad, hoy bajo su crecimiento neoliberal, se privatiza, segregando a la población urbana, e imposibilitando encuentros democráticos... ¿ tendrá acaso la revuelta algún impacto sobre estos modos de hacer ciudad, al menos en el eje de plaza Dignidad?

Baquedano en su devenir indigena y feminista. Yuxtaposición de cuerpos y estéticas que resignifican y proyectan otra ciudad

\section{IMAGEN 3}

\section{BAQUEDANO EN SU DEVENIR INDÍGENA Y FEMINISTA. YUXTAPOSICIÓN DE CUERPOS Y ESTÉTICAS QUE RESIGNIFICAN Y PROYECTAN OTRA CIUDAD}

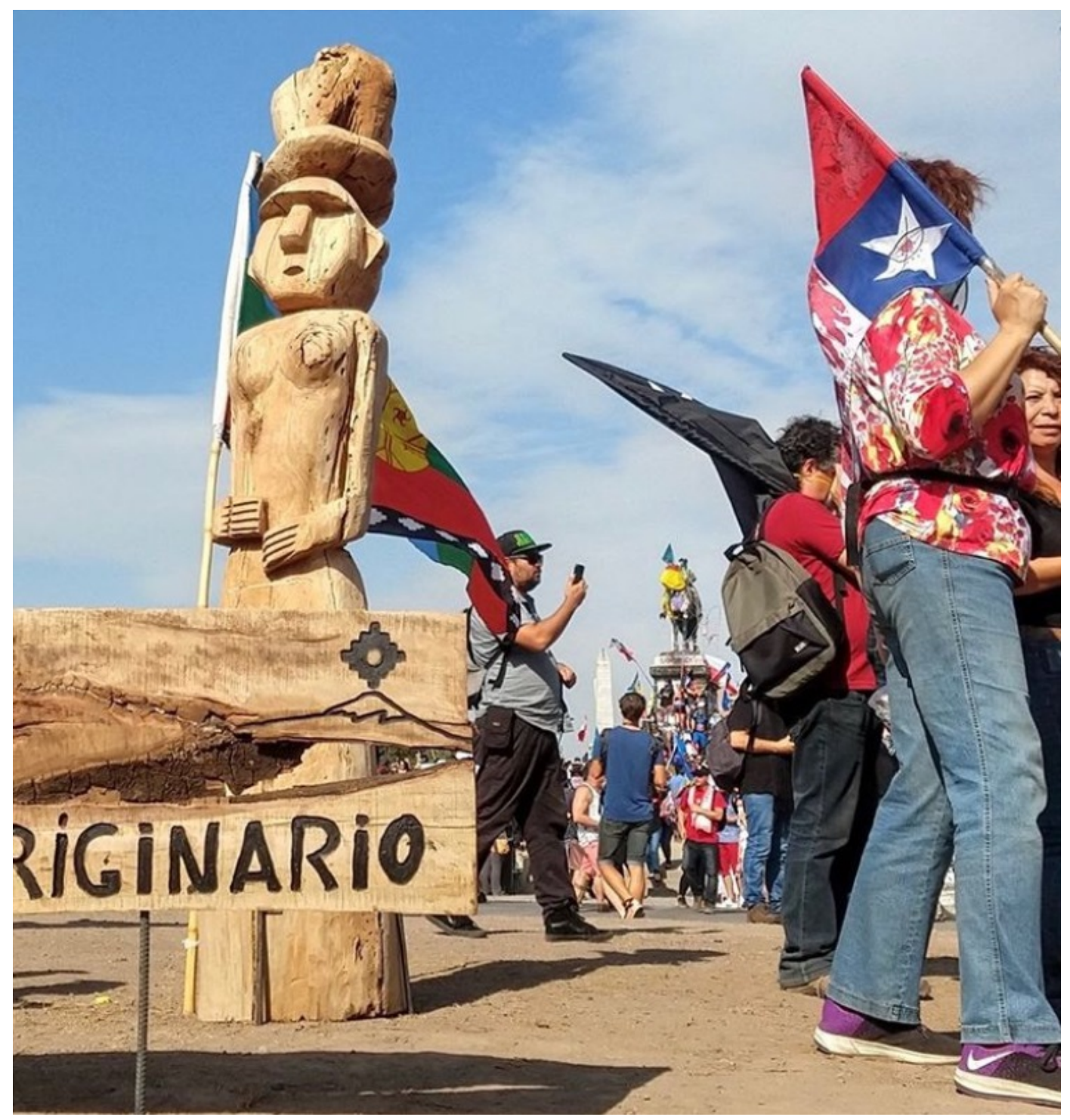

Chemamüll, intervención del colectivo Originario en Plaza Dignidad, Fotografía de Monumentos IN cómodos (“Monumento a los...”, 2019). 


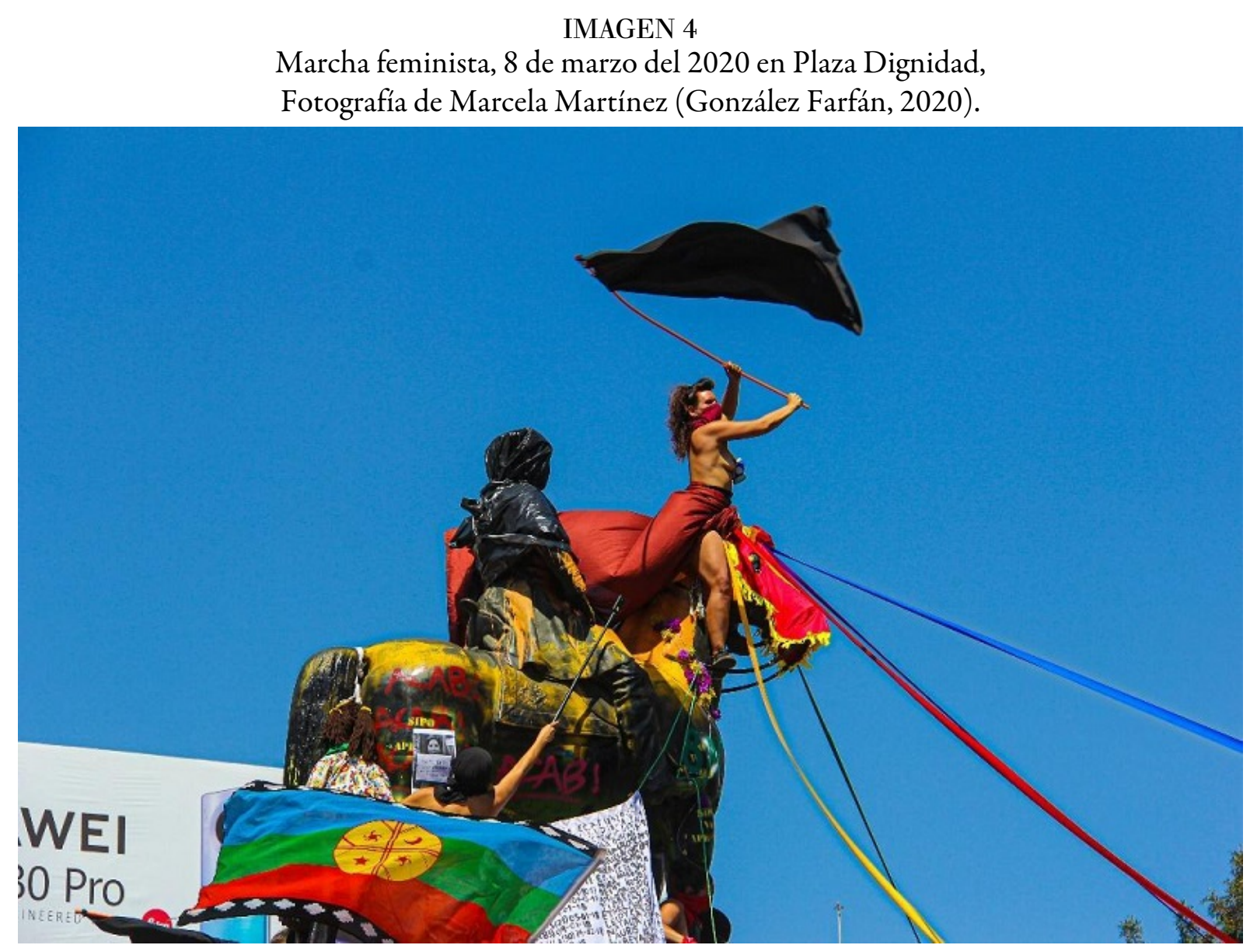

Hasta ahora, por supuesto, nada bueno se avizora. El único procedimiento que ha gestado el gobierno de Piñera sobre lo acontecido en plaza Dignidad, como hemos mostrado, ha sido el borramiento de la creatividad popular. Y todavía más, la autoridad tempranamente ha levantado el "Plan Recuperamos Chile", cuyo objetivo es reconstruir el mobiliario urbano, entre ellos los monumentos, con la intención de volver a "la normalidad", es decir, hacer como si nada hubiese pasado desde el 18 de octubre. El contexto de la pandemia, claro, ha favorecido estas intenciones. Lo que devela este plan es la nula intención de abrir procesos de participación para pensar la ciudad, lo que busca el gobierno es limitarse a tachar y blanquear el barroquismo expresado en la revuelta.

Y es ante esta tensión que emergen los repertorios ch'ixi como acciones de evidente incomodidad para la imaginación urbana neoliberal y nacionalista. Muy por el contrario, a determinados usos del arte urbano, que han sido cooptados y disciplinados por el llamado "urbanismo táctico", los rayados de la revuelta contienen una dimensión política imposible de subsumir. Hay un punto donde el barroquismo espacializado en la ciudad no puede ser cooptado por las herramientas multiculturales. Y es aquí donde emerge lo ch'ixi como otro posible repertorio para pensar los urbanismos insurgentes, dado que este gesto es antagónico a la hibridez multicultural, está más allá de las lógicas de reconocimiento a la diversidad, más que una búsqueda integracionista es la posibilidad para imaginar mundos nuevos dado que, tal como señala Silvia Rivera Cusicanqui, lo $c h^{\prime} i x i$ :

Pone de manifiesto una activa recombinación de mundos opuestos y significantes contradictorios, que forma un tejido en la frontera misma de aquellos polos antagónicos. La vitalidad de este proceso recombinatorio ensancha esta frontera, la convierte en una trama y en un tejido intermedio, taypi: arena de antagonismos y seducciones. Estos son los espacios fronterizos en los que aflora la performatividad ch'ixi de la fiesta (Rivera, 2010, p. 5). 
Así, ante la negación colonial, incluso ante las formulaciones tácticas del neoliberalismo contemporáneo, que utilizan el pregón multicultural que es en definitiva una incorporación despolitizada y folclorizada de las alteridades históricas, lo $c h$ 'ixi se presenta como una categoría descriptiva y analítica para todo aquello que habita incansablemente la frontera, diluyendo así los estandartes del guión nacional y la formación cancina del urbanismo sostenido en el definiciones unilateralmente económicas, sustrayendo el poder radical de la contaminación barroca. Y todo esto se ha desenvuelto, como hemos intentado señalar, espacialmente, ha sido la ciudad el escenario donde la "blanquitud", como ethos homogeneizante, ha buscado zurcir violentamente un relato univoco, gestando un urbanismo plagado de nociones utilitaristas, dejando los modos de habitar barroco como fallas o como meros decorados del espectáculo multicultural. Es que, lo sabemos, "la ciudad se ha ordenado de acuerdo con los intereses del poder económico y político. Así Lefebvre, desde su obra más conocida, "El derecho a la ciudad", concebía el urbanismo como una ideología al servicio del poder y una herramienta de control de la población”. Ahora bien, al mismo tiempo, y por eso defendemos todavía la noción de urbanismo, este puede ser una "posibilidad de subversión contra el mismo" (La Corrala, 2016, p.16).

Claro, nosotros reivindicamos la posibilidad de un urbanismo sostenido en los diversos modos de habitar que desarrollan los pueblos ante la imposición blanquecina, las cuales son fallas, a modo de grietas, que muchas veces son perseguidas o cooptadas para la despolitización de sus formas. Ante esto, emerge lo que se ha denominado "planificación o urbanismo insurgente", que trastoca los procedimientos de proyectar los espacios urbanos, reglados durante el neoliberalismo, como señalamos, por el capital inmobiliario y por lo que se ha entendido como los "expertos": planificadores, ingenieros, urbanistas. Muchas veces estos procedimientos, por el reclamo democratizador de los movimientos urbanos, han tenido que ser legitimados mediante procesos de consulta que, en este punto del devenir del modelo neoliberal, ya parece no dar el ancho para abrazar las exigencias por democratizar la ciudad. Con ello,

Las prácticas insurgentes generan una ruptura ontológica, ya que no se trata de conseguir una porción mayor de la torta, sino de desear otro tipo de torta - una torta ontológicamente distinta-. Las prácticas insurgentes y la planificación insurgente no buscan la inclusión a través de una mejor representación (sea de especialistas o de políticos); sino que buscan la inclusión auto-determinada, en la cual los derechos de las personas son reales y practicados (Miraftab, 2018, p. 222)

Pues bien, las prácticas ch'ixi que desmonumentalizaron por saturación y renombraron un eje central de la ciudad como plaza Dignidad, no solo impugnaron la historia, sino que corroyeron un modo de habitar la ciudad. Como práctica insurgente la Revuelta imaginó otra posibilidad para uno de los espacios centrales de Santiago. Los meses de movilización mancharon de modo iconoclasta este vértice urbano, disputando su sentido simbólico, pero al mismo tiempo, y de modo solapado, se elaboró otra comprensión del uso cotidiano de aquel espacio, que mediante la saturación comenzó a diluir los modos de valorización del suelo del capital inmobiliario en aquella zona, entrando de lleno a una disputa por la planificación futura de aquel eje central de la ciudad y el país.

En fin, nuestra Revuelta, que bajo otras posibilidades es factible de comprender bajo la categoría ch'ixi, mediante la saturación corporal y estética, y en un proceso inacabado y voluble, imaginó y proyectó otro urbanismo para el futuro, porque todo lo acontecido ocurrió realmente, haciendo impostergable un problema-grieta venidero: ¿cómo construir un urbanismo democrático luego de una Revuelta? ¿cómo hacer justicia a todos esos días de lucha y dignidad? La borradura, que ha sido la estrategia del gobierno, lo sabemos, está muy lejos de aquello. Toca entonces imaginar fórmulas y procedimientos que abracen y surjan desde la densidad barroca de memorias, gestos y estéticas de unos de los momentos más importantes de la historia reciente del país. 


\section{Palabras finales}

Hemos intentado reflexionar sobre una dimensión particular de la Revuelta, que actualmente toma ribetes fundamentales de la discusión pública: la desmonumentalización. Luego del asesinato de George Floyd, y las movilizaciones antirracistas que de ella se sucedieron tanto en Estados Unidos y Europa, donde el ejercicio de arrancan monumentos de hombres que recordaban las bestialidades del colonialismo y la esclavitud, las controversias sobre los usos políticos de la historia y la memoria han vuelto a cobrar mucha actualidad. En general las posiciones son dos, fuera de quienes defienden a ultranza al "supremacismo blanco": quienes comprender y defienden la desmonumentalización (donde, por cierto, nos encontraríamos nosotros) como gesto de un combate público por la historia y quienes comprenden pero no defienden aquel repertorio por no ceñirse a los métodos democráticos para el desenvolvimiento de aquellos combates.

No profundizaremos, pero lo que hay detrás del debate es una comprensión divergente de la democracia y los espacios posibles para su gestación. Bastaría solo decir que los actuales modelos democráticos no son posibles de comprender por una simple voluntad, hay una serie de intereses y estructuras rígidas de participación que hacen sencillamente imposible ceñirse a esos pasos para acercarse mínimamente, sobre todo para los sectores subalternizados, a gestar esos combates de modos simétricos. En fin, es un debate largo, pero que en suma implica revisar qué entendemos por democracia en tiempos neoliberales, y como ella posibilita o no al encuentro de miradas.

Ahora bien, más allá de esta discordia, creemos que hay un consenso de que los combates por la historia se encuentran muy abiertos, como en décadas no ocurría. El neoliberalismo había sostenido sus principios ideológicos en un intento por hacer desaparecer cualquier conflictividad fuera de sus marcos de comprensión mediante el axioma "el fin de la historia". No había más allá del neoliberalismo, todo era posible de reducir a cuestiones técnicas gestionados por los "expertos", entre ellos, por cierto, los planificadores. Pues bien, cuando los sentidos de la historia entran en combate, lo que se diluye realmente es el consenso sobre el futuro. Peleamos por los significados del pasado, porque allí reverberan las narrativas posibles para nuestro devenir, dado que, pensando con Benjamin: "articular el pasado históricamente no significa reconocerlo «tal y como ha sido». Significa apoderarse de un recuerdo que relampaguea en el instante de un peligro.” (2007 [1947], p. 21). Las Revueltas, por cierto, son instantes de peligro fundamentales, donde la consciencia histórica expele sobre la coyuntura, no por nada la frase "no son 30 pesos, son 30 años" adquirió tanto sentido; el peso del tiempo se puso en el centro del combate.

Así, el aforismo de un "fin de la historia" se diluyó completamente, y quedó abierto el espacio voluble e inmanejable de la utopía. Hoy, desafortunadamente, en medio de una pandemia, aquel espacio abierto se torna para nosotros apenas una grieta, pero aun así respira infatigable, resquebrajando el devenir, haciéndolo invidente en su total dimensión, nadie se puede arrogar la posición de pinotisa. Y precisamente, en esa grieta inatrapable, de algún modo todavía ingobernable por su dimensión destituyente, observamos los repertorios ch'ixi de la Revuelta como posibles avisadores de un mundo anti-señorial y contra-blanquecino, un mundo manchado de indio, de negro, de mestizaje inacabado. Y que es al mismo tiempo un modo otro de habitar la ciudad, antagónico a los modos de valorización inmobiliaria, en definitiva, una performatividad, como hay tantas en Latinoamérica, para pensar nuestros urbanismos insurgentes.

\section{REFERENCIAS}

Achugar, H. (1999). El lugar de la memoria. A propósito de monumentos (Motivos y paréntesis). En J. M. Barbero (ed.). Cultura y globalización. Bogotá: Universidad Nacional de Colombia-Facultad de Ciencias HumanasCentro de Estudios Sociales. 
Allende, M. (12 de noviembre del 2019). La parte por el todo: monumentos y gestos anticoloniales. Revista Palabra Pública. Recuperado de: https://palabrapublica.uchile.cl/2019/11/12/la-parte-por-el-todo-monumentos-y-ges tos-anticoloniales/

Amaro, F. (17 de enero de 2018). Antes y después de 10 lugares de Chile. Plataforma Arquitectura. Recuperado de https://www.plataformaarquitectura.cl/cl/887027/conoce-el-antes-y-despues-de-10-lugares-de-chile-gracia s-a-enterreno/5a5cba05f197cc13a5000010-conoce-el-antes-y-despues-de-10-lugares-de-chile-gracias-a-enterre no-imagen

Benjamin, W. (2007). Conceptos de Filosofía de la Historia. Buenos Aires: Ediciones Terramar.

Echeverría, B. (2010). Modernidad y Blanquitud. México: Ediciones Era.

Barría, M. (2020). Performar la urgencia. En F. Gaspar; G. Jarpa (Ed.). Los Futuros Imaginados. Santiago de Chile: Vicerrectoría de Investigación y Desarrollo de la Universidad de Chile.

Butler, J. (2002). Cuerpos que importan. Sobre los limites materiales y discursivos del "sexo". Buenos Aires: Editorial Paidós

Colmenares, G. (1997). Las convenciones contra la cultura. Bogotá: TM Editores.

Da Silva Catela, L (2010). Pasados en conflicto. De memorias dominantes, subterráneas y denegadas. En E. Bohoslavsky, et. al. (ed.) Problemas de historia reciente del Cono Sur. Buenos Aires: Editorial Prometeo.

De Certeau, M. (2006). La escritura de la historia. México: Universidad Iberoamericana.

De Mattos, C. (2018). Encrucijada ante los impactos críticos de un crecimiento urbano financiarizado. Documentos de Trabajo del Instituto de Estudios Urbanos y Territoriales UC (4). Recuperado de: https://estudiosurbanos.uc.cl/ documento/encrucijada-ante-los-impactos-criticos-de-un-crecimiento-urbano-financiarizado/

Fernández, F. (2018). Memorias en resistencia: festividades y ritualidades andinas en Santiago de Chile. Athenea Digital, 18(1), 269-291. doi: https://doi.org/10.5565/rev/athenea.1850

Galindo, M. (2007). Visiones aymaras sobre las autonomias. Aportes para la construcción del Estado Nacional. La Paz: Programa de Investigación Estratégica en Bolivia.

González, R. y Sampieri, S. (2018). Hablaré de la patria. Santiago de Chile: Comunas Unidas.

González Farfán, C. (11 de marzo de 2020). Habla Andrea Olivares, 'la Diosa de la Dignidad': “A todas nos han abusado de una u otra manera”. El Desconcierto. Recuperado de: https://www.eldesconcierto.cl/2020/03/11/a ndrea-olivares-diaz-la-diosa-de-la-dignidad-tiene-madre-mapuche-e-hija-capucha/

Gruzinski, S. (1994). La Guerra de las imágenes. De Cristóbal Colón a "Blade Runner" (1492 -2019). México: Fondo de Cultura Económica.

Huinca, H. (15 de noviembre del 2019). El derribo de estatuas en las plazas de Chile y Wallmapu. La desmonumentalización de los iconos de la memoria histórica colonial. Comunidad de Historia Mapuche. Recuperado de: https://www.comunidadhistoriamapuche.cl/el-derribo-de-estatuas-en-las-plazas-de-chile-y-wa llmapu-la-des-monumentalizacion-de-los-iconos-de-la-memoria-historica-colonial/

Hiernaux, D. (2007). Los imaginarios urbanos: de la teoría y los aterrizajes en los estudios urbanos. Revista Eure, 33(99), 17-30. doi: http://dx.doi.org/10.4067/S0250-71612007000200003

Jelin, E. (2002). Los trabajos de la memoria. Madrid: Siglo XXI.

La Corrala (2016). Cartografía de la ciudad capitalista. Transformación urbana y conflicto social en el Estado español. Madrid: Traficantes de sueños.

La marcha más grande de Chile (26 de octubre de 2019). Dinero. Recuperado de: https://www.dinero.com/internac ional/articulo/la-marcha-mas-grande-de-chile/278379

Leyton, C. y Huertas, R. (2012) Reforma urbana e higiene social en Santiago de Chile. La tecno-utopía liberal de Benjamín Vicuña Mackenna (1872-1875). Dynamis, 32 (1), 21-44. doi: http://dx.doi.org/10.4321/S0211-95 362012000100002

Márquez, F. (2 de diciembre del 2019). En los escombros de la ciudad neoliberal. Ciper. Recuperado de: https://cipe rchile.cl/2019/12/02/en-los-escombros-de-la-ciudad-neoliberal

Márquez, F. (2018). Patrimonio: contranarrativas urbanas. Santiago: Ediciones Universidad Alberto Hurtado. 
Martínez, J. (2019). Entre estatuas y memorias. rompiendo una(s) historia(s) de lo nacional. En M. Folchi (Ed.). Chile Despertó, lecturas desde la Historia del estallido social (pp. 28-42). Santiago de Chile: Unidad de Redes Transdisciplinarias de la Vicerrectoría de Investigación y Desarrollo de la Universidad de Chile.

Miraftab F. (2018). Insurgencia, planificación y la perspectiva de un urbanismo humano. Territorios, (38), 215-233.Recuperado de: https://revistas.urosario.edu.co/xml/357/35755496010/html/index.html

Monumento a los Pueblos Originarios en Plaza Dignidad (6 de diciembre de 2019). Monumentos INCómodos. Recuperado de: https://www.instagram.com/p/B5vvnDNpeTx/?igshid=1ueexqmadyvic

Nora, P. (2009). Les lieux de mémoire. Santiago de Chile: LOM Ediciones.

Pollak, M. (2006). Memoria, olvido, silencio. Buenos Aires: Ediciones Al Margen.

Rivera Cusicanqui, S. et al. (2010). Principio Potosí Reverso. Madrid: Museo Nacional Centro de Arte Reina Sofía.

Rivera Cusicanqui, S. (2018). Otro mundo chix’i es posible. Ensayos desde un presente en crisis. Buenos Aires: Ediciones Tinta Limón.

Salazar, J. (2006). La ciudad como texto. La crónica urbana de Carlos Monsivás. Monterrey: Universidad Autónoma de Nueva León.

Silvestri, G. (1999). Memoria y monumento. Revista Punto de Vista, (64), 42-44. Recuperado de: https://www.ahir a.com.ar/ejemplares/64/

Tapia, L. (2019). Dialéctica del colonialismo interno, Santiago de Chile: Editorial Quimantú.

Taylor, D. (2017). El archivo y el repertorio. la memoria cultural performática en las Américas. Santiago de Chile: Ediciones Universidad Alberto Hurtado.

Traverso, E. (2007). El Pasado. Instrucciones de uso. Historia, memoria, politica. Madrid: Ediciones Jurídicas y Sociales.

\section{Notas}

1 Monumentos IN Cómodos [@monumentosincomodos]. Perfil de Instagram: https://www.instagram.com/monume ntosincomodos/ 